(1/12; 8.3\%). Overall, ECMO weaning with decannulation was achieved in 14 patients $(46.6 \%)$.

Three patients died in the hospital 9, 35, and 40 days after ECMO discontinuation and decannulation for septic shock ( 2 of them were in the bridge group). The overall survival at discharge was $36.6 \%$ (11/30 patients).

\section{DISCUSSION}

ECMO support is currently required to allow a patient's recovery after cardiac surgery, after cardiopulmonary arrest refractory to resuscitation maneuvers, or after severe respiratory damage. $^{3-5} \mathrm{~A}$ specialized 24-hour in-house ECMO team is usually necessary to monitor patient's parameters continuously to guarantee the best possible outcome ${ }^{1-4}$; this requires a great economic investment and is generally possible in large-volume pediatric heart centers with great financial resources.

The weaning from ECMO support is always a delicate phase in the management of heart and lung recovery, and constant observation of the patient's hemodynamic status is mandatory, together with continuous flushing of the circuit and cannulas when ECMO is temporarily stopped to prevent the risk of clot formation and systemic embolism. $^{2-3}$ In our unit, because of the lack of a dedicated 24-hour in-house ECMO team, a strict and tireless cooperation among cardiac surgeons, nursing personnel, and perfusionists is essential for buffering our limited resources. For these reasons, we have developed the simplified weaning bridge, which allows us to observe the patients during the first critical 24 hours after ECMO weaning with the ECMO circuit recirculating at the bed space and ready to be restarted in a few seconds if needed.

The simplified weaning bridge can be used without additional human and economic resources. With the bridge, ECMO can be restarted fast and safely (so long as it was not discontinued for any hemorrhagic or thromboembolic complications) just by removing 2 tubing clamps, without emergency resuscitation maneuvers or a new cannulation, thus obviating the need for surgeons or other specialized technicians. The introduction of the simplified weaning bridge into our therapeutic armamentarium allows us to be more liberal in the process of weaning patients from ECMO because of the easy possibility of restarting the support.

\section{References}

1. Thiagarajan RR, Laussen PC, Rycus PT, Bartlett RH, Bratton SL. Extracorporeal membrane oxygenation to aid cardiopulmonary resuscitation in infants and children. Circulation. 2007;116:1693-700.

2. Shuhaiber J, Thiagarajan RR, Laussen PC, Fynn-Thompson F, del Nido P, Pigula F. Survival of children requiring repeat extracorporeal membrane oxygenation after congenital heart surgery. Ann Thorac Surg. 2011;91:1949-55.

3. Kane DA, Thiagarajan RR, Wypij D, Scheurer MA, Fynn-Thompson F, Emani S, et al. Rapid-response extracorporeal membrane oxygenation to support cardiopulmonary resuscitation in children with cardiac disease. Circulation. 2010;122(11 Suppl):S241-8.

4. Aharon AS, Drinkwater DC Jr, Churchwell KB, Quisling SV, Reddy VS, Taylor M, et al. Extracorporeal membrane oxygenation in children after repair of congenital cardiac lesions. Ann Thorac Surg. 2001;72:2095-102.

5. Vida VL, Rubino M, Stellin G. Prolonged ECMO support for virus-induced cardiorespiratory failure early after cardiac surgery. Pediatr Cardiol. 2006;27: $122-3$.

\title{
Occult gastrointestinal bleeding in patients with a left ventricular assist device axial flow pump: Diagnostic tools and therapeutic algorithm
}

\author{
Vincenzo Tarzia, MD, ${ }^{\mathrm{a}}$ Carlo Dal Lin, MD, ${ }^{\mathrm{a}}$ Tomaso Bottio, MD, PhD, ${ }^{\mathrm{a}}$ Stefano Benvenuti, MD, ${ }^{\mathrm{b}}$ \\ Fausto Chilovi, MD, ${ }^{\mathrm{b}}$ and Gino Gerosa, $\mathrm{MD},{ }^{\mathrm{a}}$ Padova and Bolzano, Italy
}

\footnotetext{
From the Division of Cardiac Surgery, ${ }^{\text {a }}$ Department of Cardiac, Thoracic, and Vascular Sciences, Padova University, Padova, Italy; and the Gastroenterology Unit, ${ }^{\mathrm{b}}$ Bolzano Hospital, Bolzano, Italy.

Disclosures: Authors have nothing to disclose with regard to commercial support.

Received for publication July 7, 2011; revisions received Nov 23, 2011; accepted for publication Jan 6, 2012; available ahead of print Feb 3, 2011.

Address for reprints: Vincenzo Tarzia, Division of Cardiac Surgery, Department of Cardiac, Thoracic, and Vascular Sciences, University of Padua, Via Giustiniani, 2, 35128 Padova, Italy (E-mail: v.tarzia@gmail.com).

J Thorac Cardiovasc Surg 2012;143:e28-31

0022-5223/\$36.00

Copyright (c) 2012 by The American Association for Thoracic Surgery

doi:10.1016/j.jtcvs.2012.01.033
}

Gastrointestinal (GI) bleeding is a common and serious problem in patients with continuous-flow left ventricular assist devices (LVADs). ${ }^{1,2}$ Thus in a clinical context it is crucial to adopt the most effective diagnostic strategy and where possible use noninvasive procedures to limit the infective and hemorrhagic burden.

We report the case of a patient with significant GI bleeding after implantation of a Jarvik 2000 LVAD (Jarvik Heart, Inc, New York, NY). The sources of the bleeding were successfully identified by wireless PillCam SB capsule videoendoscopy (VCE) (Given Imaging, Yoqneam, Israel) 

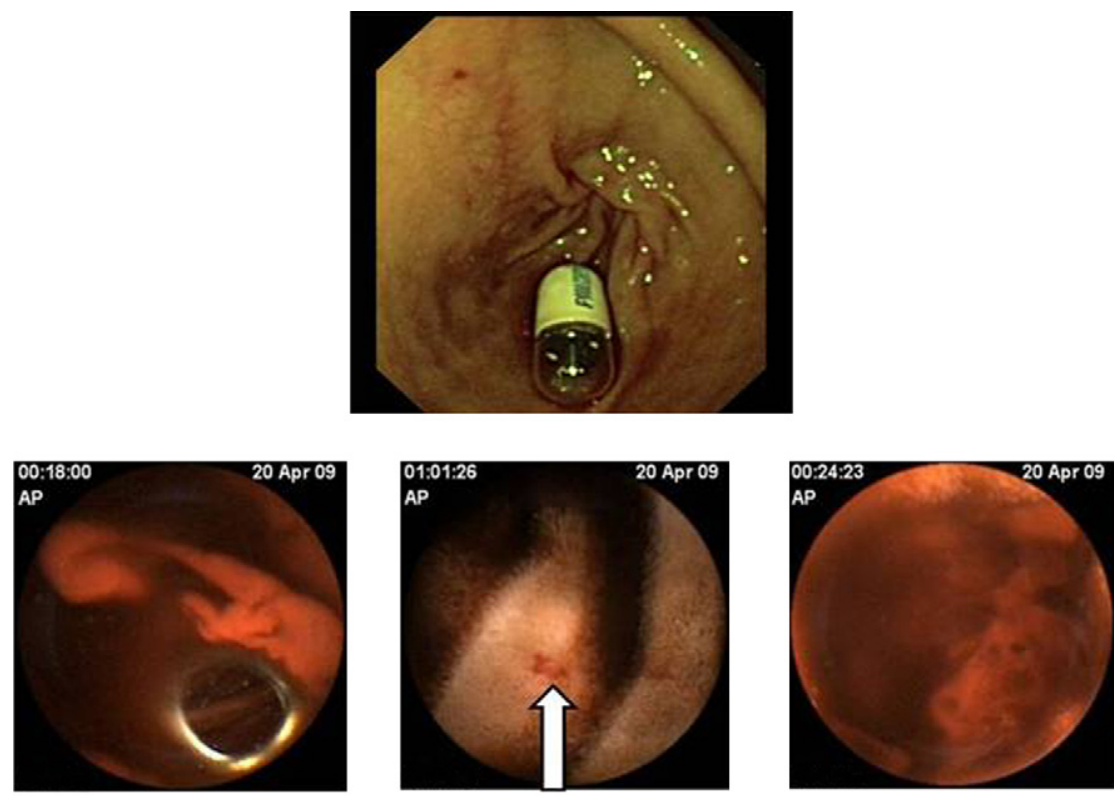

A

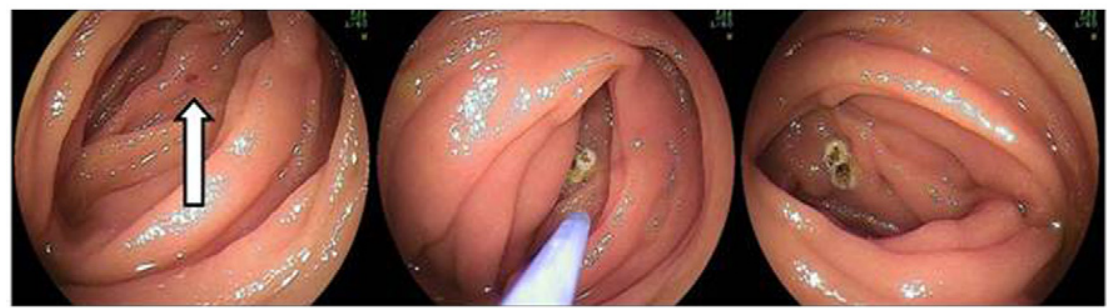

B
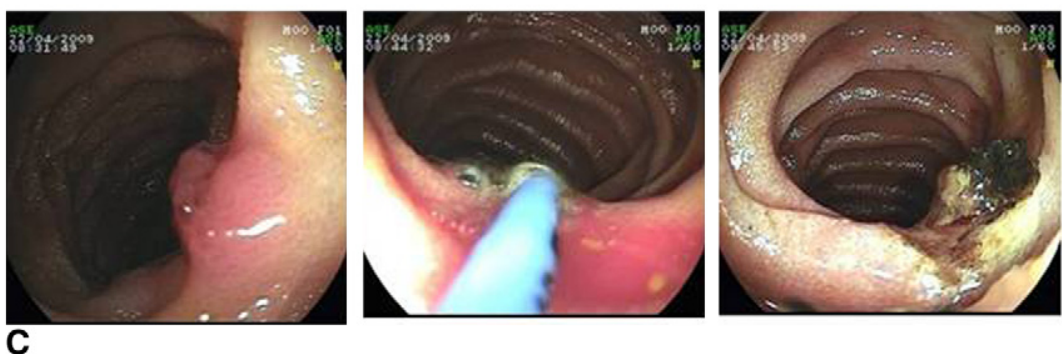

FIGURE 1. A, PillCam SB capsule videoendoscope showing several jejunal lesions with active bleeding and small bowel angiodysplasias. B, Several angiodyplasias were successfully treated with argon plasma coagulation during double balloon enteroscopy. C, Dieulafoy lesion was successfully treated with argon plasma coagulation during double balloon enteroscopy.

and were successfully treated by argon plasma coagulation during a double balloon enteroscopy (DBE).

\section{CLINICAL SUMMARY}

A 69-year-old man with a history of large anterior wall myocardial infarction, coronary artery bypass graft, implantable cardioverter-defibrillator (ICD) implantation, and renal failure was admitted to our institution for refractory heart failure despite maximal medical treatment. He was assessed as suitable for destination therapy with implantation of a Jarvik 2000 LVAD, which was performed through a left thoratocomy without cardiopulmonary bypass. The early postoperative course was largely uneventful.

Intravenous heparin (activated partial thromboplastin time, 50-55 seconds) and then oral warfarin were administered with the aim of achieving an international normalized ratio of 2.0 to 2.5 .

A dose of $100 \mathrm{mg}$ of aspirin was given daily from the second postoperative day. 


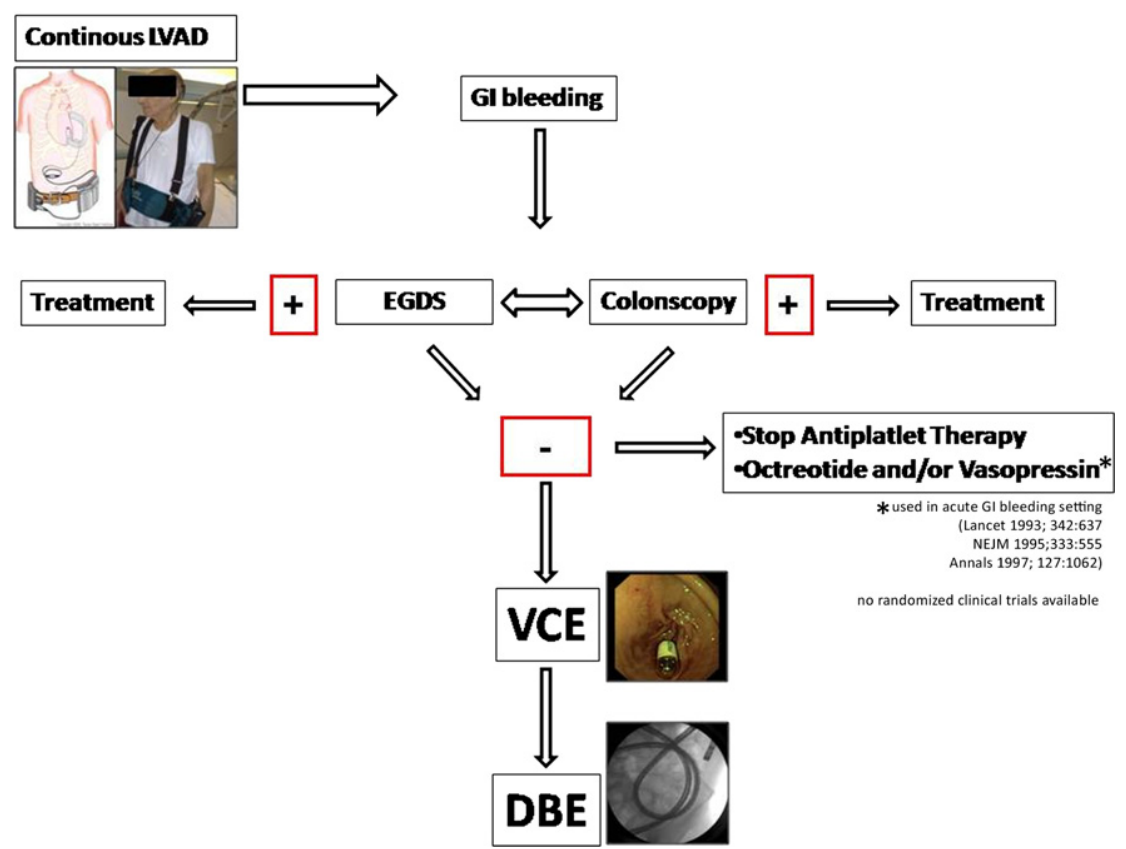

FIGURE 2. Diagnostic and therapeutic algorithm for occult gastrointestinal (GI) bleeding in a patient with a left ventricular assist device (LVAD). EGDS, Esophagogastroduodenoscopy; VCE, PillCam SB capsule videoendoscopy; DBE, double balloon enteroscopy.

The antithrombotic treatment was monitored and calibrated after thromboelastometry (ROTEM; Tem International $\mathrm{GmbH}$, Munich, Germany) to avoid both a hypercoagulant or hypocoagulant state and aggregometry (Multiplate analyzer; Dynabyte Informationssysteme $\mathrm{GmbH}$, Munich, Germany) serial evaluations to adjust the antiplatelet therapy.

One month after implantation, the patient began having dark, foul-smelling stools. Esophagogastroduodenoscopy and colonscopy revealed no pathologic findings. Aspirin and warfarin were discontinued and low molecular weight heparin was introduced. The patient underwent several blood transfusions and subcutaneous octreotide treatment did not resolve the bleeding. During the following days, melena persisted and the hemoglobin concentration decreased. A push enteroscopy revealed 2 angiodysplasias with active bleeding that were treated with argon plasma coagulation.

Nevertheless, melena and anemia persisted and bleeding from the small intestine appeared to be most likely. After conventional preparation, wireless VCE was performed with the PillCam SB2 capsule endoscope. There were no problems with passage of the capsule or signal transmission, and no malfunction of the Jarvik 2000 and ICD occurred. Analysis of the data captured revealed several jejunal lesions with active bleeding and small bowel angiodysplasias (Figure 1, A). A deep DBE was performed with the assistance of a cardiothoracic surgeon and cardiac anesthesiologist. The patient was kept supine and care was taken to avoid upper abdominal pressure on or near the LVAD. With an initial oral approach under general anesthesia, 6 angiodyplasias distal to the ligament of Treiz and 1 distal jejunal Dieulafoy lesion were successfully treated with argon plasma coagulation (Figure 1, $B$ and $C$ ). The rectal approach under sedation revealed no lesions. Both procedures were uneventful. The patient had no further GI bleeding and was discharged home 1 week after the procedure. Once the bleeding was stopped, we restarted oral warfarin alone, achieving an international normalized ratio of 2.0 to 2.5 without further complications.

\section{DISCUSSION}

GI bleeding is a widely known complication in patients with LVADs, and its occurrence is promoted by multiple comorbidities present and the need for antithrombotic therapy. Additionally, continuous-flow LVADs may cause an acquired von Willebrand disease contributing to bleeding in the presence of GI angiodisplasias. ${ }^{3-5}$ These vascular malformations may be located anywhere in the GI tract, and it may be necessary to visualize the entire small intestine if esophagogastroduodenoscopy and colonoscopy are nondiagnostic. In this situation it is crucial to proceed with the most accurate diagnostic strategy, paying attention to use noninvasive procedures to limit the infective and hemorragic risks. To this end, wireless VCE and deep DBE have become important diagnostic and therapeutic tools. There is some concern that wireless 
signal transmission from the capsule might be disturbed by the electromagnetic field of the LVAD or ICD. ${ }^{3-6}$ On the other hand, the LVAD and ICD could be disturbed by the capsule. In our case, no interactions were observed among the Jarvik 2000, the ICD (CONTAK RENEWAL TR cardiac resynchronization therapy pacemaker; Boston Scientific, Boston, Mass), and the PillCam SB2 capsule endoscope. Although wireless VCE is a good noninvasive diagnostic tool able to scan the entire bowel, the source of bleeding could not be identified owing to its intermittent nature. However, it is possible to perform a DBE as a diagnostic and therapeutic procedure, potentially guided by the VCE results. The DBE is a somewhat invasive procedure able to treat the AVMs and is a good alternative to surgical laparotomy. On the other hand, DBE requires accurate management: the procedure has to be performed under the surveillance of a cardiothoracic surgeon and cardiac anesthesiologist. The patient must be sedated, intubated, kept supine, and supported by inotropes to face the anesthetic vasoplegia. In our case the DBE was performed using the $9.5-\mathrm{mm}$ enteroscope Fujinon EN-450T5; t-type (Fujinon Inc, Saitama city, Japan). ${ }^{7}$

More important, in patients with LVADs, it is crucial to avoid excessive upper abdominal pressure because this may lead to the reduction of venous blood return impairing the preload required for correct LVAD function.

There have only been a few written reports on VCE and DBE in patients with LVADs. ${ }^{1,3,7,8}$ However, our case is the first in which DBE treatment of AVMs and a Dieulafoy lesion have been successfully guided by VCE results.
In conclusion, we suggest this diagnostic and therapeutic algorithm (Figure 2) in the patient with continuous-flow LVAD and occult GI bleeding. It can allow the detection (VCE) of lesions in the reach of a therapeutic enteroscope (DBE), avoiding the need for more invasive tests, including mesenteric angiography, exploratory laparotomy, or ontable enteroscopy.

\section{References}

1. Letsou GV, Shah N, Gregoric ID, Myers TJ, Delgado R, Frazier OH. Gastrointestinal bleeding from arteriovenous malformations in patients supported by the Jarvik 2000 axial-flow left ventricular assist device. J Heart Lung Transplant. 2005;24:105-9.

2. Crow S, John R, Boyle A, Shumway S, Liao K, Colvin-Adams M, et al. Gastroin testinal bleeding rates in recipients of nonpulsatile and pulsatile left ventricular assist devices. J Thorac Cardiovasc Surg. 2009;137:208-15.

3. Bechtel JF, Wellhöner P, Charitos EI, Bucsky B, Morshuis M, Sievers HH. Localizing an occult gastrointestinal bleeding by wireless PillCam SB capsule videoendoscopy in a patient with the HeartMate II left ventricular assist device. J Thorac Cardiovasc Surg. 2010;139:e73-4.

4. Geisen U, Heilmann C, Beyersdorf F, Benk C, Berchtold-Herz M, Schlensak C, et al. Non-surgical bleeding in patients with ventricular assist devices could be explained by acquired von Willebrand disease. Eur J Cardiothorac Surg. 2008; 33:679-84

5. Crow S, Chen D, Milano C, Thomas W, Joyce L, Piacentino V 3rd, et al. Acquired von Willebrand syndrome in continuous-flow ventricular assist device recipients. Ann Thorac Surg. 2010;90:1263-9.

6. Matthews JC, Betley D, Morady F, Pelosi F Jr. Adverse interaction between a left ventricular assist device and an implantable cardioverter defibrillator. J Cardiovasc Electrophysiol. 2007;18:1107-8.

7. Decker GA, Miller ED, Pasha SF, Harrison ME, Leighton JA. Deep enteroscopy in patients with left ventricular assist devices: practical and technical considerations. Endoscopy. 2010;42:E194.

8. Seow CH, Zimmerman MJ. Capsule endoscopy in the detection of small-intestinal bleeding in patients supported by a nonpulsatile axial-flow Jarvik 2000 left ventricular assist device. Gastrointest Endosc. 2006;63:1087. 